\title{
Targeted-Volume Noninvasive Ventilation Reduces Extubation Failure in Postextubated Medical Intensive Care Unit Patients: A Randomized Controlled Trial
}

\author{
Vorawut Thanthitaweewat ${ }^{1}$, Dittapol Muntham ${ }^{2,3}$, Naricha Chirakalwasan ${ }^{1,2}$ \\ 1Department of Medicine, Division of Pulmonary and Critical Care medicine, Faculty of Medicine, Chulalongkorn University, Bangkok, Thailand, \\ 2Excellence Center for Sleep Disorders, King Chulalongkorn Memorial Hospital, Thai Red Cross Society, Bangkok, Thailand, \\ ${ }^{3}$ Faculty of Science and Technology, Rajamangala University of Technology Suvarnabhumi, Phranakhon Si Ayutthaya, Thailand
}

\section{Abstract}

Purpose: Till date, the benefit of using noninvasive ventilation (NIV) routinely after extubation to prevent reintubation has been conflicting. We aim to demonstrate the effect of targeted-volume NIV for the prevention of reintubation and extubation failure after planned extubation in medical intensive care unit (ICU) patients. Study Design: This was a prospective, randomized controlled study. Materials and Methods: Patients on invasive mechanical ventilation for more than $48 \mathrm{hrs}$ for acute respiratory failure, who were ready for extubation, were randomized into targeted-volume NIV (intervention group) or oxygen mask (controlled group) immediately after extubation and continuously for 24 hrs. Results: A total of 58 patients were enrolled in this study. The targeted-volume NIV group was observed to have a trend toward lower reintubation rate within $48 \mathrm{hrs}$ compared to oxygen mask group $(0 \%$ vs. $17.2 \% ; P=0.052)$. Extubation failure rate within 48 hrs was significantly lower in targeted-volume NIV group compared to oxygen mask group $(0 \%$ vs. $41.38 \% ; P<0.001)$. There was a trend toward lower ICU length of stay (6[5] days vs. 10[8] days (median interquartile range [IQR]); $P=0.053$ ) as well as shorter hospital length of stay after extubation (10[19] days vs. 18[15] days (median [IQR]); $P=0.059)$. There were no differences in the incidence of ventilator-associated pneumonia (VAP)/hospital-acquired pneumonia (HAP) $(6.90 \%$ vs. 20.69\%; $P=0.253)$ and 28 day-mortality $(13.79 \%$ vs. 20.69\%; $P=0.487)$. Conclusions: Our study is the first study to demonstrate the benefit of application of targeted-volume NIV immediately after extubation in reducing extubation failure rate. There was a trend toward lowering reintubation rate and shorter ICU length of stay and hospital length of stay after extubation in mixed medical ICU patients.

Keywords: Acute respiratory failure, postextubation, reintubation, targeted-volume non-invasive ventilation

\section{INTRODUCTION}

Noninvasive ventilation (NIV) is one of the interventions that have been used to facilitate weaning and prevent reintubation. Previous studies demonstrated the benefit of NIV in reduction of mortality, ventilator-associated pneumonia (VAP), and intensive care unit (ICU) and hospital length of stay. ${ }^{[1-3]} \mathrm{NIV}$ was proven to be beneficial in chronic obstructive pulmonary disease (COPD) exacerbation, ${ }^{[4]}$ cardiogenic pulmonary edema, ${ }^{[5]}$ and postsurgery patients. ${ }^{[6]}$ For postextubation, the benefit of NIV in reduction of reintubation rate was primarily demonstrated in high-risk groups including advance age and cardiac or pulmonary diseases..$^{[3,7,8]}$ However, the benefit of utilization of NIV during postextubation in mixed medical ICU population has been conflicting. ${ }^{[7,9-11]}$

\begin{tabular}{|l|l|}
\hline \multicolumn{3}{c|}{ Access this article online } \\
\hline Quick Response Code: & Website: \\
& www.ijccm.org \\
& \\
\end{tabular}

NIV has physiological benefit from positive end-expiratory pressure (PEEP) and pressure support (PS). PEEP is known to increase alveolar size and recruitment, improve gas exchange, improve lung compliance, reduce intrapulmonary shunt, and reduce work of breathing. ${ }^{[12,13]}$ PS can improve alveolar ventilation and allows some respiratory muscle rest during the inspiratory phase.

Targeted-volume NIV, bilevel positive airway pressure, allows for the setting of fixed tidal volume (TV) in which

Address for correspondence: Dr. Naricha Chirakalwasan, 1873 Rama IV Road, Bangkok 10330, Thailand. E-mail: narichac@hotmail.com

This is an open access journal, and articles are distributed under the terms of the Creative Commons Attribution-NonCommercial-ShareAlike 4.0 License, which allows others to remix, tweak, and build upon the work non-commercially, as long as appropriate credit is given and the new creations are licensed under the identical terms.

For reprints contact: reprints@medknow.com

How to cite this article: Thanthitaweewat V, Muntham D, Chirakalwasan N. Targeted-volume noninvasive ventilation reduces extubation failure in postextubated medical Intensive Care Unit patients: A randomized controlled trial. Indian J Crit Care Med 2018;22:639-45. 
the system output automatically adjusts pressure to achieve the predetermined TV. Targeted-volume NIV has only been previously studied in obesity hypoventilation syndrome, ${ }^{[14,15]}$ COPD, ${ }^{[16]}$ hypercapnic respiratory failure, ${ }^{[17]}$ and chest wall deformity population. ${ }^{[18]}$ We hypothesized that the application of targeted-volume NIV immediately after planned extubation would decrease reintubation rate, extubation failure rate, and other outcomes compared to standard oxygen therapy. At present, targeted-volume ventilation mode has been installed in many commercially available NIV devices.

\section{Materials and Methods}

\section{Study design}

This study was a randomized, controlled trial, conducted during the period from May 2016 to February 2017, in 16-bed medical ICU. This study was approved by the Ethics Committee, and this study was also registered to Clinical Trial website.

\section{Patients' selection}

Patients, who passed weaning process by spontaneous breathing trial with low-pressure support ventilation or T-piece, and met the readiness criteria for extubation, ${ }^{[19]}$ without excessive copious secretion, passed cough leak test, and vital sign stability without high-dose vasopressor, were enrolled in the study. ${ }^{[20]}$ Inclusion criteria were as follows: (a) age 18 years or older; (b) on invasive mechanical ventilation for a period longer than 48 hrs due to acute respiratory failure; (c) already weaned from invasive mechanical ventilation and ready for extubation; (d) and no facial abnormality or trauma or recent facial surgery. Exclusion criteria were as follows: (a) tracheostomized patients; (b) previous intubation in this current admission; (c) intubation due to COPD exacerbation or cardiogenic pulmonary edema; (d) and refusal to participate in the study. Informed consents were obtained from patients or the designated next of kin of the patients.

\section{Randomization}

Eligible patients were randomly assigned into $1: 1$ ratio to the application of targeted-volume NIV or oxygen mask. Randomization into assigned groups was performed using a mixed block. Assigned group randomizations were placed in sealed opaque envelopes which were labeled with the order of randomization.

\section{Targeted-volume noninvasive ventilation}

After extubation, proper size full face silicone mask (Amara Respironics full face mask, size S, M, and L) was fitted for each patient and adjusted to confirm and ensure patients' comfort. Average volume-assured PS (AVAPS) (Philips Respironics) machines were utilized in this study. The device was set at the targeted, delivered TV of $6 \mathrm{ml} / \mathrm{kg}$ of ideal body weight. End-expiratory positive airway pressure (EPAP) was set at $4 \mathrm{~cm}$ of water or equal to the last PEEP level of the invasive mechanical ventilation setting. Minimum inspiratory positive airway pressure (IPAP minimum ) was set equal to EPAP $+4 \mathrm{~cm}$ of water, and maximum inspiratory positive

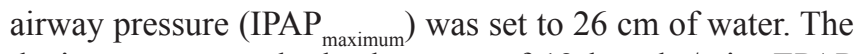
device was set at the backup rate of 12 breaths/min. EPAP was increased by $2 \mathrm{~cm}$ of water to maintain $\mathrm{SpO} 2$ above $90 \%$. Humidification Level 2 was also utilized during the study. In addition, $6 \mathrm{lpm}$ of oxygen supplementation was added to targeted-volume NIV through T-connector. The targeted-volume NIV with $6 \mathrm{lpm}$ of oxygen supplementation was utilized continuously for 24-h postextubation. After $24 \mathrm{~h}$ of usage, NIV was replaced by a nasal oxygen cannula.

\section{Oxygen mask}

Patients assigned to oxygen mask group were administrated simple oxygen mask with humidification at fixed oxygen flow of $6 \mathrm{lpm}$ immediately after extubation. After $24 \mathrm{hrs}$ of usage, an oxygen mask was replaced by a nasal oxygen cannula.

\section{Monitoring}

All patients in the study received standard nursing care in medical ICU and were monitored for vital signs (heart rate, respiratory rate, and blood pressure) and oxygen saturation. Blood gas was drawn from an arterial line or radial artery at baseline, 30 mins, $2 \mathrm{hrs}$, and $24 \mathrm{hrs}$ after extubation. Patients were followed up until discharge or at least 28 days after extubation.

\section{Outcomes}

The primary outcome of this study was reintubation rate within $48 \mathrm{hrs}$ after extubation. Extubation failure rate within $48 \mathrm{hrs}$, reintubation rate within 28 days, mortality (both in ICU and in hospital), hospital or ventilator associated pneumonia (HAP/ VAP), and ICU and hospital length of stay were monitored as the secondary outcomes of the study. We also collected data of patients' comfort by using visual analog scale (VAS) and side effects of the device such as pressure sore, nasal congestion, facial pain, and serious complications including aspiration, hypotension, and pneumothorax.

We defined patients with extubation failure as follows: unstable blood pressure (systolic blood pressure $>180 \mathrm{mmHg}$ or $<90 \mathrm{mmHg}$ ), extreme tachycardia (heart rate $>140 \mathrm{bpm}$ ), life-threatening cardiac arrhythmia, respiratory distress (respiratory rate $>30$ breaths/min), decreased level of consciousness, uncontrolled agitation, hypoxemia $(\mathrm{PaO} 2<60 \mathrm{mmHg}$ ) or hypercapnia $(\mathrm{PaCO} 2>50 \mathrm{mmHg})$, and inability to clear secretion. ${ }^{[9]}$ If patients met the extubation failure criteria, reintubation might be considered. However, the decision for reintubation or using other rescue interventions, such as NIV or high-flow nasal cannula (HFNC), to prevent reintubation was made by ICU physicians to reduced bias of investigators.

\section{Statistical analysis}

Since the study of Ornico et al. reported reintubation rate in NIV and oxygen mask group were $5 \%$ and $39 \%$, respectively. ${ }^{[9]}$ We used the study power of $80 \%$ and $\alpha$-error of $5 \%$ and calculated sample size to be 52 patients ( 26 patients in each group). We expected dropout rate of $10 \%$; hence, the final calculated sample size was 58 patients (29 patients in each intervention). 
Quantitative variables were compared between two interventions using Student's $t$-test or Mann-Whitney U test. Chi-squared or Fisher's exact test was used to compare proportion between groups. For consecutive measurement for repeated data, we used the analysis of the linear mixed-effect model. The Kaplan-Meier curve was used to estimate the probability of intubation free after extubation. The study was analyzed by using intention-to-treat analysis. Stata version 12.1 software was utilized.

\section{RESULTS}

From May 2016 to February 2017, 588 patients were admitted to medical ICU. A total of 438 patients were excluded since they did not meet the inclusion criteria. Thirty-eight patients declined to participate in the study. Fifty-four patients met the exclusion criteria. Finally, 58 patients were enrolled in the study and randomized into two groups. One patient in the targeted-volume NIV group discontinued the device immediately after the trial due to pressure intolerance. This patient was analyzed in the targeted-volume NIV group according to the intention-to-treat analysis protocol [Figure 1].

Targeted-volume NIV group and oxygen mask group were similar in baseline characteristics as shown in Table 1. All patients were followed up until discharge from the hospital.

No reintubation within $48 \mathrm{hrs}$ was observed in targeted-volume NIV group whereas five patients in the oxygen mask group $(17.24 \%)$ were reintubated $(P=0.052)$ [Figure 2]. Furthermore, no one in targeted-volume NIV group developed extubation failure compared to 12 patients in oxygen mask group $(41.38 \%)(P<0.001)$. In those 12 patients who developed extubation failure within 48 hrs, five patients were reintubated $(17.24 \%)$, five patients received rescue conventional targeted-pressure NIV (17.24\%), and two patients received rescue HFNC (6.89\%) [Figure 3]. Among 12 patients who developed extubation failure, causes of extubation failure included respiratory distress (33.33\%), hypoxemia (33.33\%), hypercapnia $(16.67 \%)$, extreme tachycardia $(8.33 \%)$, and inability to clear secretion $(8.33 \%)$.

There was a trend toward lower ICU length of stay in targeted-volume NIV group compared to oxygen mask group (6[5] days vs. 10[8] days (median interquartile range [IQR]);

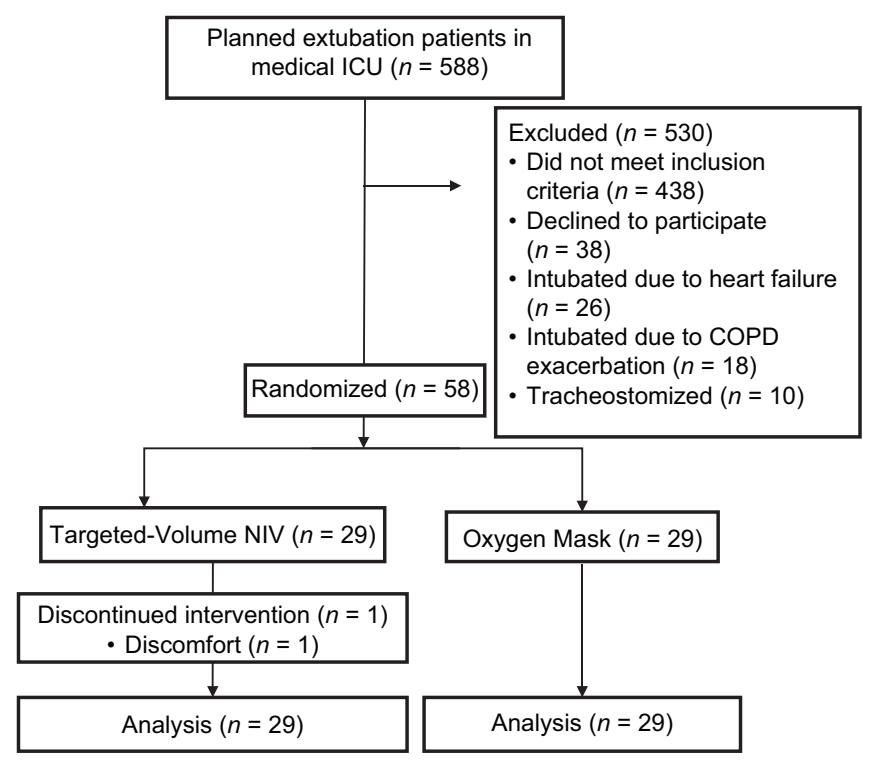

Figure 1: Flow of the study

\section{Table 1: Baseline characteristics}

\begin{tabular}{|c|c|c|c|}
\hline Baseline characteristic & Targeted-volume NIV $(n=29)$ & Oxygen mask $(n=29)$ & $P$ \\
\hline Age (years)* & $63.41 \pm 21.82$ & $62.72 \pm 18.88$ & 0.898 \\
\hline Gender (male/female) & $19 / 10$ & $20 / 9$ & 0.780 \\
\hline BMI* & $22.06 \pm 4.60$ & $22.86 \pm 7.45$ & 0.627 \\
\hline \multicolumn{4}{|l|}{ Cause of respiratory failure, $n(\%)$} \\
\hline Pneumonia & $17(58.62)$ & $17(58.62)$ & 0.442 \\
\hline Sepsis & $8(27.59)$ & $10(34.48)$ & \\
\hline Duration of previous invasive MV (days) $)^{\S}$ & $4(5)$ & $7(7)$ & 0.194 \\
\hline APACHE II score at ICU admission* & $18.34 \pm 5.78$ & $20.45 \pm 7.31$ & 0.229 \\
\hline APACHE II score at extubation* & $10.17 \pm 4.23$ & $11.45 \pm 4.76$ & 0.285 \\
\hline \multicolumn{4}{|l|}{ Underlying, $n(\%)$} \\
\hline COPD & $2(6.90)$ & $2(6.90)$ & 1.000 \\
\hline Cardiovascular disease & $5(17.24)$ & $7(25.93)$ & 0.429 \\
\hline Chronic kidney disease & $5(17.24)$ & $3(10.34)$ & 0.446 \\
\hline Malignancy & $5(17.24)$ & $7(25.93)$ & 0.429 \\
\hline $\begin{array}{l}\text { Patients with high risk (age }>65 \text { years old and } / \text { or } \\
\text { the presence of cardiac or pulmonary diseases) }(\%)\end{array}$ & $20(68.97)$ & $16(55.17)$ & 0.279 \\
\hline Before extubation $\mathrm{PaO}_{2}(\mathrm{mmHg}) *$ & $122.06 \pm 49.16$ & $117.51 \pm 44.53$ & 0.714 \\
\hline Before extubation $\mathrm{PaCO}_{2}(\mathrm{mmHg})^{*}$ & $32.02 \pm 3.41$ & $33.02 \pm 5.46$ & 0.403 \\
\hline Before extubation $\mathrm{PaO}_{2}$ and $\mathrm{FiO}_{2}$ ratio & $329.68(103.51)$ & $359(179.25)$ & 0.981 \\
\hline
\end{tabular}


Thanthitaweewat, et al.: Targeted-volume noninvasive ventilation reduces extubation failure

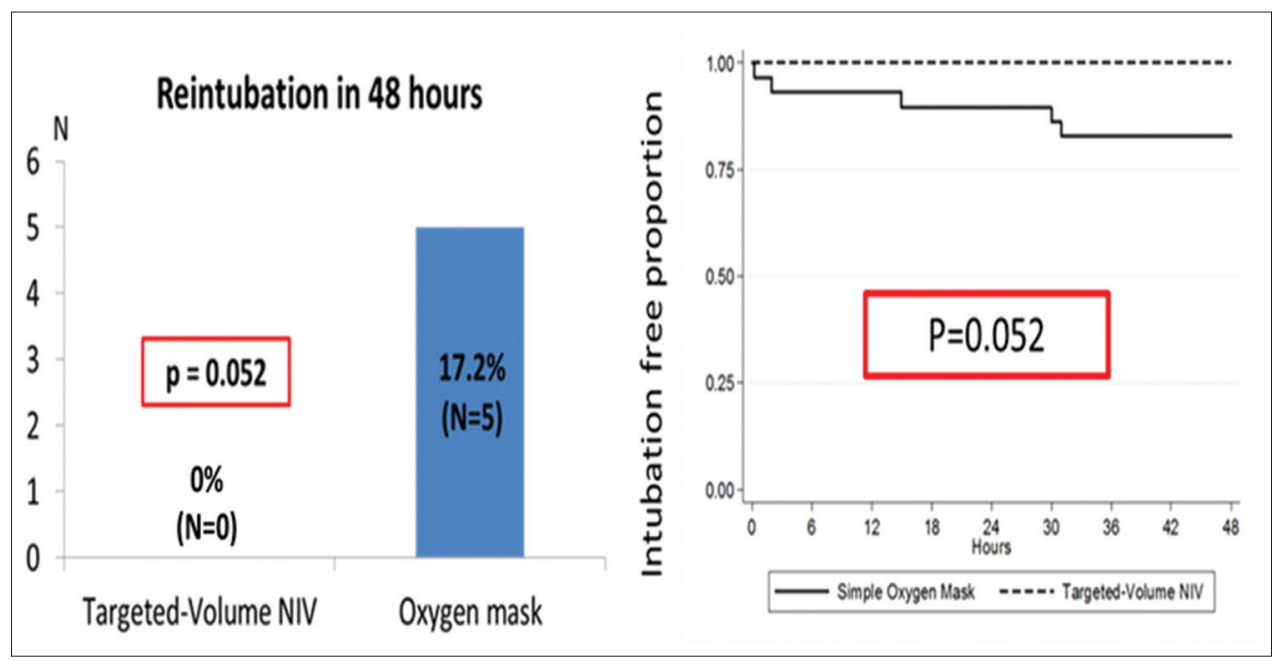

Figure 2: Primary outcome-bar chart (left) showed comparison of reintubation rate within $48 \mathrm{hrs}$, and the Kaplan-Meier curve (right) showed comparison of intubation-free proportion within $48 \mathrm{hrs}$ after extubation

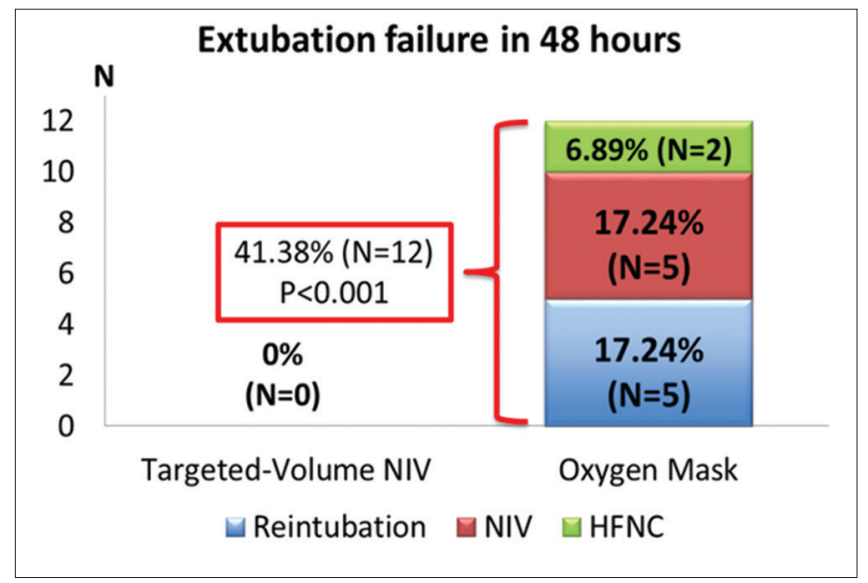

Figure 3: Comparison of extubation failure rate within $48 \mathrm{hrs}$

$P=0.053)$ as well as shorter hospital length of stay after extubation (10[19] days vs. 18[15] days (median [IQR]); $P=0.059$ ). The incidence of VAP, HAP, and 28-day mortality was not different between two groups [Table 2].

Despite lower $\mathrm{PaO} 2$ observed in the targeted-volume NIV group at 30 mins and $2 \mathrm{hrs}$, the difference was not statistically significant at $24 \mathrm{hrs}(P=0.510) . \mathrm{PaO} 2$ values were also normal throughout the monitoring period in targeted-volume NIV group. There was no statistically significant difference in $\mathrm{PaCO} 2$ between two groups. However, heart rate and respiratory rate were lower in targeted-volume NIV group as shown in Figure 4.

The targeted-volume NIV setting, delivery values, leakage data, and hours of usage are shown in Table 3. Patients' discomfort assessed by VAS was not different between groups except mask leakage was more frequently observed in the targeted-volume NIV group (46.43\%) compared to $0 \%$ in oxygen mask group. No serious complications, including hypotension, aspiration, or pneumothorax, were observed during the study.

\section{Discussion}

Our study demonstrates the benefit of targeted-volume NIV in reducing extubation failure rate when it was applied prophylactically during postextubation in mixed medical ICU patients. We also observed a trend toward reduction in reintubation rate within $48 \mathrm{hrs}$.

There are different strategies for applying NIV in the postextubation period: for weaning (weaning strategy) in cases of weaning difficulties (one or more spontaneous breathing trial failures), to prevent postextubation failure (preventive strategy) or to treat postextubation failure (curative or rescue strategy). ${ }^{[21]}$

According to currently available data, the use of NIV immediately postextubation as a preventive strategy in high-risk group may offer benefit. Thille et al., recently, showed the benefit of prophylactic NIV after extubation in reduction of reintubation in high-risk medical ICU patients. ${ }^{\left[{ }^{[8]}\right.}$ However, their study also included postoperative patients $(20 \%)$. The previous meta-analysis by Bajaj et al. also demonstrated that the use of NIV in high-risk group resulted in reduction in reintubation, ${ }^{[7]}$ concurrent with recent recommendation from the American College of Chest Physicians and American Thoracic Society which endorsed the use of NIV during postextubation only in high-risk group. ${ }^{[22]}$

Nevertheless, the benefit of the routine use of NIV to prevent reintubation has been conflicting. Paper by Ornico et al. demonstrated a significant reduction in reintubation with the use of NIV during postextubation. ${ }^{[9]}$ However, their study included some proportion of COPD (35\%), cardiogenic pulmonary edema (10\%), and postsurgery patients $(25 \%)$ which may have favored the outcome of the NIV group.

Our study is the first study that utilized targeted-volume NIV during postextubation as the preventive strategy in mixed medical ICU patients. Reduction in extubation failure was 


\begin{tabular}{|c|c|c|c|}
\hline Outcome & Targeted-volume NIV $(n=29)$ & Oxygen mask $(n=29)$ & $P$ \\
\hline Reintubation within 48 h (\%) & 0 & $5(17.24)$ & 0.052 \\
\hline Extubation failure within $48 \mathrm{~h}(\%)$ & 0 & $12(41.38)$ & $<0.001$ \\
\hline Reintubation within 28 days (\%) & $8(27.59)$ & $12(41.38)$ & 0.269 \\
\hline ICU LOS (days) $)^{\S}$ & $6(5)$ & $10(9)$ & 0.053 \\
\hline ICU LOS after extubation (days) $)^{\S}$ & $1.38(1)$ & $2(4)$ & 0.103 \\
\hline Hospital LOS (days) $)^{\S}$ & $23(27)$ & $24(17)$ & 0.331 \\
\hline Hospital LOS after extubation (days) $)^{\S}$ & $10(19)$ & $18(15)$ & 0.059 \\
\hline Incidence of VAP/HAP (\%) & $2(6.90)$ & $6(20.69)$ & 0.253 \\
\hline In-hospital mortality (\%) & $5(17.24)$ & $8(27.59)$ & 0.345 \\
\hline 28-day mortality (\%) & $4(13.79)$ & $6(20.69)$ & 0.487 \\
\hline $\mathrm{PaO}_{2}$ at $24 \mathrm{~h}$ after extubation* & $109.80 \pm 34.52$ & $129.28 \pm 50.77$ & 0.392 \\
\hline $\mathrm{PaCO}_{2}$ at $24 \mathrm{~h}$ after extubation* & $31.91 \pm 3.88$ & $33.98 \pm 6.04$ & 0.263 \\
\hline Lactate $(\mathrm{ng} / \mathrm{ml})^{*}$ & $1.24 \pm 0.53$ & $1.55 \pm 1.23$ & 0.469 \\
\hline
\end{tabular}

*Mean \pm SD, ${ }^{\circledR}$ Median (IQR). LOS: Length of stay; ICU: Intensive care unit; SD: Standard deviation; IQR: Interquartile range; NIV: Noninvasive ventilation; VAP: Ventilator-associated pneumonia; HAP: Hospital-associated pneumonia

\begin{tabular}{|c|c|}
\hline Targeted-volume NIV information & Values \\
\hline \multicolumn{2}{|l|}{ Targeted-volume NIV settings } \\
\hline Tidal volume $(\mathrm{ml})^{*}$ & $363.79 \pm 47.69$ \\
\hline Tidal volume $(\mathrm{ml} / \mathrm{kg})^{*}$ & $6.11 \pm 0.27$ \\
\hline $\operatorname{EPAP}\left(\mathrm{cmH}_{2} \mathrm{O}\right)^{*}$ & $4.89 \pm 0.90$ \\
\hline $\mathrm{IPAP}_{\min }\left(\mathrm{cmH}_{2} \mathrm{O}\right)^{*}$ & $8.86 \pm 0.91$ \\
\hline $\operatorname{IPAP}_{\max }(\mathrm{cmH} 2 \mathrm{O})^{*}$ & 26.00 \\
\hline \multicolumn{2}{|l|}{ Delivery values } \\
\hline Tidal volume $(\mathrm{ml})^{*}$ & $512.03 \pm 98.17$ \\
\hline Tidal volume $(\mathrm{ml} / \mathrm{kg})^{*}$ & $8.63 \pm 1.41$ \\
\hline $\operatorname{IPAP}\left(\mathrm{cmH}_{2} \mathrm{O}\right)^{*}$ & $9.86 \pm 1.32$ \\
\hline $\operatorname{EPAP}\left(\mathrm{cmH}_{2} \mathrm{O}\right) *$ & $4.66 \pm 0.83$ \\
\hline Leakage data (lpm)* & $57.86 \pm 20.44$ \\
\hline Hours of usage $(\mathrm{hrs})^{\S}$ & $19.77(1.61)$ \\
\hline
\end{tabular}

observed with the use of targeted-volume NIV in our study despite excluding COPD exacerbation and cardiogenic pulmonary edema population.

Even though reintubation rate after extubation in the targeted-volume NIV group appeared to be lower than oxygen mask group, the difference did not achieve statistically significance $(P=0.052)$. Our study allowed the attending ICU physician to utilize other rescue interventions besides reintubation when extubation failure developed, as the real-world practice fashion. This strategy could have caused falsely low reintubation rate in our study since this strategy apparently prevented reintubation in extubation failure patients in our study. However, this practice has to be conducted with caution. Prior studies had demonstrated that the use of NIV in the group of extubation failure as curative or rescue strategy may be associated with higher mortality. ${ }^{[23,24]}$ Subgroup analysis of the high-risk groups defined as age $>65$ years old and/or the presence of cardiac or pulmonary diseases revealed similar results (data not shown).

Conventional targeted-pressure NIV was not tested against targeted-volume NIV in our study. However, we hypothesized that the targeted-volume NIV might be more suitable than conventional targeted-pressure NIV due to more steady TV. In this study, respiratory rate and heart rate during postextubation were significantly lower in targeted-volume NIV group compared to oxygen mask group which may indicate reduction in work of breathing from respiratory muscle resting ${ }^{[0,25]}$ [Figure 4]. On the other hand, excessive TV may result in an excessive leakage, causing suboptimal benefit of NIV and may lead to NIV failure. Recent study on NIV outcome demonstrated that high expiratory TV (Vte) was associated with NIV failure particularly when Vte was above $9.5 \mathrm{ml} / \mathrm{kg}$ of predicted body weight. ${ }^{[26]}$ In this study, the mean Vte was optimal $(8.63 \pm 1.41 \mathrm{ml} / \mathrm{kg})$. Excessive TV and high transpulmonary pressure could potentially promote ventilator-induced lung injuries associated with detrimental outcomes. ${ }^{[27]}$ However, the difference between the setup and the delivered TV $(6.11 \pm 0.27 \mathrm{vs} 8.63 \pm 1.41 \mathrm{ml} / \mathrm{kg})$ was observed in our study most likely explained by the patients' own inspiratory effort. This is an important message that targeted-volume NIV mode is not totally risk free, and surveillance is still required. We also demonstrated that the targeted-volume NIV was well tolerated with minor observed side effects.

Previous studies in targeted-volume NIV demonstrated its benefit in obesity hypoventilation syndrome, ${ }^{[14,15]} \mathrm{COPD},{ }^{[16]}$ hypercapnic respiratory failure, ${ }^{[17]}$ and chest-wall deformity population. ${ }^{[18]}$ Our study demonstrated the safety and feasibility of the use of targeted-volume NIV in postextubation as the preventive strategy and our preliminary data demonstrated its efficacy to decrease extubation failure. In general, reintubation rate is modest at around $10 \%-20 \% .{ }^{[28]}$ However, extubation failure has been shown to be associated with many detrimental 


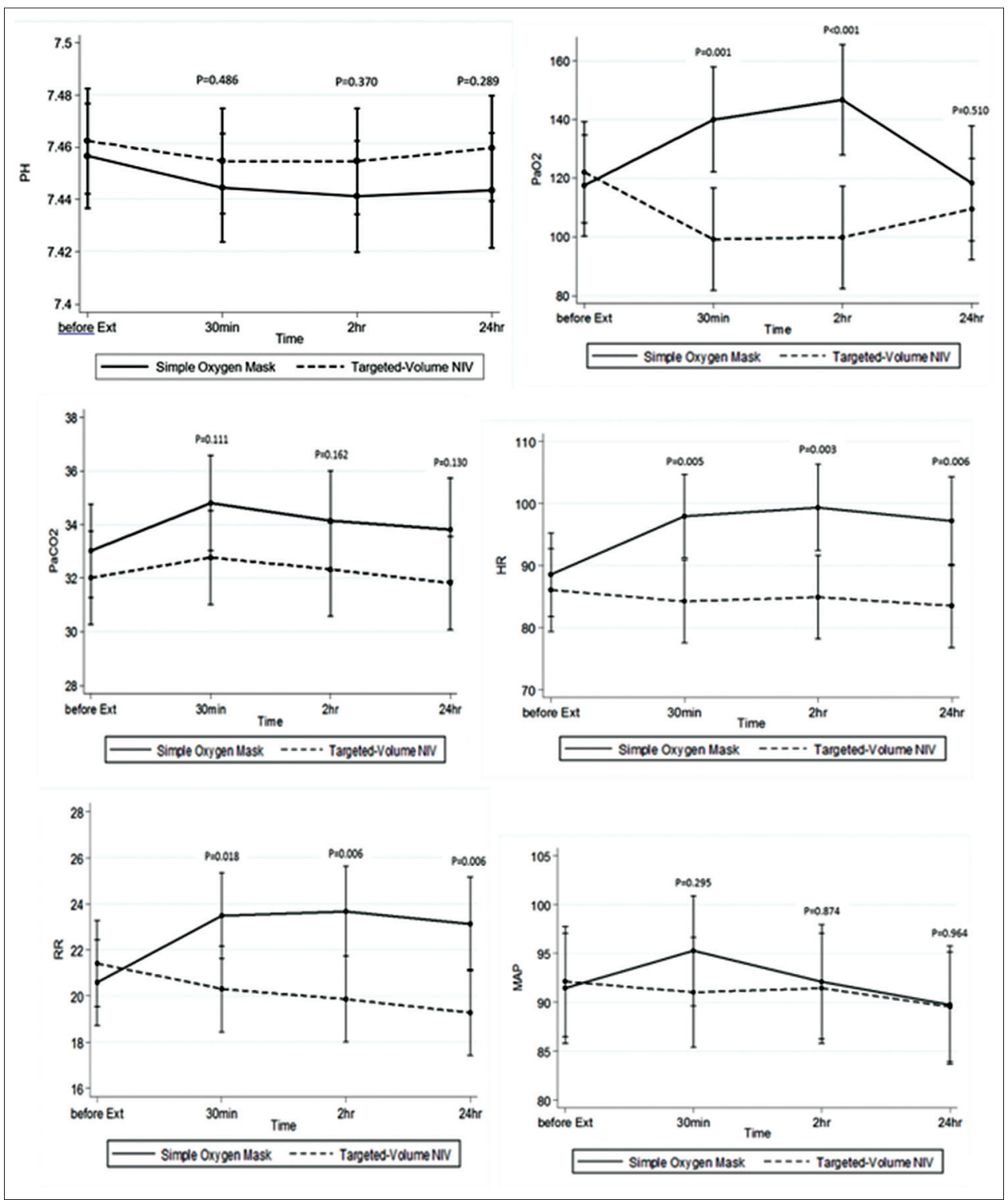

Figure 4: $\mathrm{pH}, \mathrm{PaO}_{2}, \mathrm{PaCO}_{2}$, heart rate, respiratory rate, and mean arterial pressure during the first $48 \mathrm{hrs} \mathrm{comparing} \mathrm{oxygen} \mathrm{mask} \mathrm{and} \mathrm{targeted-volume}$ noninvasive ventilation

outcomes including increased mortality, increased ICU, and hospital length of stay as well as increased incidence of VAP. ${ }^{[2]}$ We believe that the use of targeted-volume NIV could be of benefit in this postextubation period as the preventive strategy. However, further study on cost-effectiveness of utilization of this intervention is crucial.

\section{Limitation}

Our study was a single-center study with relatively small sample size; hence, multicenter study with larger sample size is warrant. We only studied the reintubation and extubation failure rates within $48 \mathrm{hrs}$ as we utilized the previously defined terms. ${ }^{[30-32]}$ The outcomes of reintubation and extubation failure rates after $48 \mathrm{hrs}$ might be of benefit as some studies demonstrated that the reintubation rate can occur up to 7 days. ${ }^{[33]}$ Conventional targeted-pressure NIV and HFNC were not utilized for comparison in our study, as we aimed to compare targeted-volume NIV with standard oxygen therapy. In perspective, targeted-volume NIV could be formally tested against targeted-pressure NIV and/or HFNC in the future study.

\section{Conclusions}

Targeted-volume NIV in immediate postextubation in mixed medical ICU patients as the preventive strategy showed benefit in reduction of extubation failure within $48 \mathrm{hrs}$ after extubation and a trend toward reduction in reintubation rate in $48 \mathrm{hrs}$, ICU length of stay, and hospital length of stay after extubation.

\section{Acknowledgments}

All AVAPS machines and related equipment were sponsored by Philips Respironics Company. However, the company has no impact on study design or interpretation of the result of the study. 


\section{Financial support and sponsorship}

This research has been financially supported by the Ratchadaphiseksomphot Endowment Fund of Chulalongkorn University.

\section{Conflicts of interest}

There are no conflicts of interest.

\section{ReFERENCES}

1. Antonelli M, Bello G. Noninvasive mechanical ventilation during the weaning process: Facilitative, curative, or preventive? Crit Care 2008; 12:136.

2. Ferrer M, Valencia M, Nicolas JM, Bernadich O, Badia JR, Torres A, et al. Early noninvasive ventilation averts extubation failure in patients at risk: A randomized trial. Am J Respir Crit Care Med 2006;173:164-70.

3. Nava S, Gregoretti C, Fanfulla F, Squadrone E, Grassi M, Carlucci A, et al. Noninvasive ventilation to prevent respiratory failure after extubation in high-risk patients. Crit Care Med 2005;33:2465-70.

4. Brochard L, Mancebo J, Wysocki M, Lofaso F, Conti G, Rauss A, et al. Noninvasive ventilation for acute exacerbations of chronic obstructive pulmonary disease. N Engl J Med 1995;333:817-22.

5. Gray A, Goodacre S, Newby DE, Masson M, Sampson F, Nicholl J, et al. Noninvasive ventilation in acute cardiogenic pulmonary edema. N Engl J Med 2008;359:142-51.

6. Squadrone V, Coha M, Cerutti E, Schellino MM, Biolino P, Occella P, et al. Continuous positive airway pressure for treatment of postoperative hypoxemia: A randomized controlled trial. JAMA 2005;293:589-95.

7. Bajaj A, Rathor P, Sehgal V, Shetty A. Efficacy of noninvasive ventilation after planned extubation: A systematic review and meta-analysis of randomized controlled trials. Heart Lung 2015;44:150-7.

8. Thille AW, Boissier F, Ben-Ghezala H, Razazi K, Mekontso-Dessap A, Brun-Buisson $\mathrm{C}$, et al. Easily identified at-risk patients for extubation failure may benefit from noninvasive ventilation: A prospective before-after study. Crit Care 2016;20:48.

9. Ornico SR, Lobo SM, Sanches HS, Deberaldini M, Tófoli LT, Vidal AM, et al. Noninvasive ventilation immediately after extubation improves weaning outcome after acute respiratory failure: A randomized controlled trial. Crit Care 2013;17:R39.

10. Figueroa-Casas JB. Preventive use of noninvasive ventilation after planned extubation. Respir Care 2012;57:318-20.

11. Su CL, Chiang LL, Yang SH, Lin HI, Cheng KC, Huang YC, et al. Preventive use of noninvasive ventilation after extubation: A prospective, multicenter randomized controlled trial. Respir Care 2012;57:204-10.

12. Dehaven CB Jr., Hurst JM, Branson RD. Postextubation hypoxemia treated with a continuous positive airway pressure mask. Crit Care Med 1985;13:46-8.

13. Lindner KH, Lotz P, Ahnefeld FW. Continuous positive airway pressure effect on functional residual capacity, vital capacity and its subdivisions. Chest 1987;92:66-70.

14. Storre JH, Seuthe B, Fiechter R, Milioglou S, Dreher M, Sorichter S, et al. Average volume-assured pressure support in obesity hypoventilation: A randomized crossover trial. Chest 2006;130:815-21.

15. Janssens JP, Metzger M, Sforza E. Impact of volume targeting on efficacy of bi-level non-invasive ventilation and sleep in obesity-hypoventilation. Respir Med 2009;103:165-72.

16. Briones Claudett KH, Briones Claudett M, Chung Sang Wong M,
Nuques Martinez A, Soto Espinoza R, Montalvo M, et al. Noninvasive mechanical ventilation with average volume assured pressure support (AVAPS) in patients with chronic obstructive pulmonary disease and hypercapnic encephalopathy. BMC Pulm Med 2013;13:12.

17. Cao Z, Luo Z, Hou A, Nie Q, Xie B, An X, et al. Volume-targeted versus pressure-limited noninvasive ventilation in subjects with acute hypercapnic respiratory failure: A multicenter randomized controlled trial. Respir Care 2016;61:1440-50.

18. Struik FM, Duiverman ML, Meijer PM, Nieuwenhuis JA, Kerstjens HA, Wijkstra PJ, et al. Volume-targeted versus pressure-targeted noninvasive ventilation in patients with chest-wall deformity: A pilot study. Respir Care 2011;56:1522-5.

19. Khamiees M, Raju P, DeGirolamo A, Amoateng-Adjepong Y, Manthous CA. Predictors of extubation outcome in patients who have successfully completed a spontaneous breathing trial. Chest 2001;120:1262-70.

20. MacIntyre NR. The ventilator discontinuation process: An expanding evidence base. Respir Care 2013;58:1074-86.

21. Bello G, De Pascale G, Antonelli M. Noninvasive ventilation. Clin Chest Med 2016;37:711-21.

22. Ouellette DR, Patel S, Girard TD, Morris PE, Schmidt GA, Truwit JD, et al. Liberation from mechanical ventilation in critically ill adults: An official American College of Chest Physicians/American Thoracic Society Clinical Practice Guideline: Inspiratory pressure augmentation during spontaneous breathing trials, protocols minimizing sedation, and noninvasive ventilation immediately after extubation. Chest 2017:151:166-80.

23. Keenan SP, Powers C, McCormack DG, Block G. Noninvasive positive-pressure ventilation for postextubation respiratory distress: A randomized controlled trial. JAMA 2002;287:3238-44.

24. Esteban A, Frutos-Vivar F, Ferguson ND, Arabi Y, Apezteguía C, González $\mathrm{M}$, et al. Noninvasive positive-pressure ventilation for respiratory failure after extubation. N Engl J Med 2004;350:2452-60.

25. Tulaimat A, Gueret RM, Wisniewski MF, Samuel J. Association between rating of respiratory distress and vital signs, severity of illness, intubation, and mortality in acutely ill subjects. Respir Care 2014;59:1338-44.

26. Carteaux G, Millán-Guilarte T, De Prost N, Razazi K, Abid S, Thille AW, et al. Failure of noninvasive ventilation for de novo acute hypoxemic respiratory failure: Role of tidal volume. Crit Care Med 2016;44:282-90.

27. Girault C, Ferrer M, Torres A. Non-invasive ventilation in hypoxemic acute respiratory failure: Is it still possible? Intensive Care Med 2017;43:243-5.

28. Esteban A, Alía I, Gordo F, Fernández R, Solsona JF, Vallverdú I, et al. Extubation outcome after spontaneous breathing trials with T-tube or pressure support ventilation. The Spanish lung failure collaborative group. Am J Respir Crit Care Med 1997;156:459-65.

29. Burns KE, Adhikari NK, Meade MO. A meta-analysis of noninvasive weaning to facilitate liberation from mechanical ventilation. Can J Anaesth 2006;53:305-15.

30. Epstein SK. Extubation. Respir Care 2002;47:483-92.

31. Epstein SK. Decision to extubate. Intensive Care Med 2002;28:535-46.

32. Hess DR. The role of noninvasive ventilation in the ventilator discontinuation process. Respir Care 2012;57:1619-25.

33. Girault C, Bubenheim M, Abroug F, Diehl JL, Elatrous S, Beuret P, et al. Noninvasive ventilation and weaning in patients with chronic hypercapnic respiratory failure: A randomized multicenter trial. Am J Respir Crit Care Med 2011;184:672-9. 